\title{
ANALISIS PERBANDINGAN KINERJA KEUANGAN BANK SYARIAH DEVISA DENGAN BANK SYARIAH NON DEVISA PERIODE 2012 - 20141)
}

\author{
Yuli Muhayati \\ Mahasiswa Program Studi S1 Ekonomi Islam - Fakultas Ekonomi dan Bisnis - Universitas \\ Airlangga \\ Email:yuli.muhayati-12@feb.unair.ac.id \\ Raditya Sukmana \\ Departemen Ekonomi Syariah - Fakultas Ekonomi dan Bisnis - Universitas Airlangga \\ Email: raditya-s@feb.unair.ac.id
}

\begin{abstract}
:
This study aims to compare and see the differences between foreign Islamic bank and non-foreign Islamic bank by using method RGEC (Risk Profile, Good Corporate Governance, Earnings, and Capital). This study examines the comparison in financial performance of four foreign Islamic banks and 6 non-foreign Islamic banks. The collection of data in this study was done by collecting all the annual reports of banks that has been created as a sample over the period 2012-2014.

The test result of the Independent Samples T-test showed there was no differences in the financial performance of foreign Islamic banks exchange with Non-foreign Islamic Bank exchange as seen from the aspect of Risk profile (NPF and FDR), GCG, Earnings (ROA), and (CAR). While there are differences of financial performance as seen fromEarnings (NOM) aspect.

Keywords: Financial performance, Foreign Exchange Banks and Non foreign exchange, RGEC
\end{abstract}

\section{PENDAHULUAN}

\section{Latar Belakang}

Industri Perbankan di Indonesia sangat penting peranannya dalam perekonomian suatu negara sebagai lembaga perantara keuangan. Hal ini dikarenakan perbankan merupakan salah satu lembaga yang mempunyai peran untuk mempertemukan antara pemilik dan pengguna dana. Oleh karena itu, kegiatan bank harus berjalan secara efisien pada skala makro maupun mikro. Untuk meningkatkan mobilisasi dana masyarakat yang selama ini belum terlayani oleh sistem perbankan konvensional dan untuk mengakomodasi kebutuhan terhadap layanan jasa perbankan yang sesuai dengan prinsip syariah, maka tahun 1992 bank syariah secara resmi diperkenalkan kepada masyarakat (Wahyuningsih, 2012).

Perkembangan yang signifikan di bidang perbankan syariah terjadi pada tahun 2008, yakni dengan dibuatnya Undang-Undang Nomor 21 tahun 2008 tentang perbankan syariah. Keluarnya Undang-Undang dimaksud sejalan dengan tujuan pembangunan nasional Indonesiauntuk mencapai terciptanya masyarakat yang adil dan amkmur berdasarkan dempkrasi ekonomi, denganmengembangkan sistem ekonomiberlandaskan pada nilai keadilan,

kebersamaan,pemerataan,pemanfaatan ,yang sesuai prinsip syariah (Ansori, 2009:7).

1) Jurnal ini merupakan bagian dari skripsi yang ditulis oleh Yuli Muhayati, NIM: 041211431 160, yang diuji pada bulan 10 Juni 2016. 
Muhayati, ef al/Jurnal Ekonomi Syariah Teori dan Terapan Vol. 4 No. 2 Februari 2017: 101-116; ANALISIS PERBANDINGAN KINERJA KEUANGAN BANK SYARIAH DEVISA DENGAN BANK SYARIAH NON DEVISA PERIODE 2012 2014

Untuk memperluas segi funding maupun lending, Bank Indonesia telah mengijinkan bank syariah beroperasi menjadi bank devisa dimana bank dapat melaksanakan transaksi keluar negeri atau yang berhubungan dengan mata vang asing secara keseluruhan, misalnya transferkeluar negeri, inkaso keluar negeri, travelers chegue, pembukaan danpembayaran letter of credit (L/C)dan transaksi luar negeri lainya.Dalam mengukur tingkat kinerja perbankan, Bank Indonesia menerbitkan peraturan yaitu peraturan bank Indonesia Nomor: 13/1/PBI/2011 tentang penilaian tingkat kesehatan bank umum, dimana bank wajib melakukan penilaian tingkat kesehatan bank secara self assesment yang meliputi aspek risiko, GCG (Good Corporate Governance), Rentabilitas (Earning), dan permodalan (Capital) atau yang disingkat dengan RGEC. Pedoman perhitungan selengkapnya diatur dalam Surat Edaran Bank Indonesia No. 13/24/DPNP tanggal 25 Oktober 2011 perihal Penilaian Tingkat Kesehatan Bank Umum.

Dengan adanya peraturan baru di atas maka bank-bank di Indonesia mulai melakukan perbaikan kinerja tidak terkecuali bank umum syariah (BUS). BUS sendiri sampai saat ini berjumlah 12 bank dimana terdapat 4 bank umum syariah devisa dan 7 bank umum syariah non devisa yang memiliki ruang lingkup dan transaksi berbeda, 1 bank campuran dan 1 unit usaha syariah yang baru menjadi bank umum syariah yaitu bank BTPN
Syariah. Yang lebih lengkapnya dapat dilihat dalam tabel berikut:

Tabel 1.

Daftar Bank Syariah Devisa dan Bank Syariah non Devisa

\begin{tabular}{|c|l|c|l|}
\hline No & $\begin{array}{l}\text { Bank Syariah } \\
\text { Devisa }\end{array}$ & No & $\begin{array}{l}\text { Bank Syarian } \\
\text { Non Devisa }\end{array}$ \\
\hline 1 & $\begin{array}{l}\text { Bank Syariah } \\
\text { Mandiri }\end{array}$ & 1 & BRI Syariah \\
\hline 2 & $\begin{array}{l}\text { Bank } \\
\text { Muamalat } \\
\text { Indonesia }\end{array}$ & 2 & BCA Syariah \\
\hline 3 & $\begin{array}{l}\text { Bank Mega } \\
\text { Syariah }\end{array}$ & 3 & $\begin{array}{l}\text { Bank Bukopin } \\
\text { Syariah Panin }\end{array}$ \\
\hline 4 & BNI Syariah & 4 & $\begin{array}{l}\text { Bank Pariah } \\
\text { Syaria BJB }\end{array}$ \\
\hline & 5 & $\begin{array}{l}\text { Bank } \\
\text { Syariah }\end{array}$ \\
\hline & & 6 & $\begin{array}{l}\text { Bank Victoria } \\
\text { Syariah }\end{array}$ \\
\hline & & 7 & BTPN Syariah \\
\hline
\end{tabular}

Sumber: Otoritas Jasa Keuangan, 2015.

Dengan melakukan penelitian tentang Bank Devisa dan Bank Non Devisa akan memberikan gambaran atas kelebihan dan kekurangan yang terdapat dalam kinerja keuangan Bank devisa dan Bank Non Devisa sehingga dengan mengetahui kekuatan bank, dan dapat dimanfaatkan untuk pengembangan usaha bank. Sedangkan kelemahannya dapat dijadikan dasar untuk perbaikan di masa mendatang. Selain itu jika Bank Devisa dan Bank Non Devisa diteliti maka juga akan mengetahui apakah fungsi intermediasi Bank Devisa dan Bank Non Devisa telah berjalan baik atau tidak. Dengan demikian, dalam masalah kinerja antara Bank Syariah Devisa dan Bank Syariah Non Devisa masih perlu diteliti dan lebih lanjut.Berdasarkan latar belakang di atas, maka rumusan masalah dari penelitian ini adalah sebagai berikut: 
Muhayati, et al/Jurnal Ekonomi Syariah Teori dan Terapan Vol. 4 No. 2 Februari 2017: 101-116; ANALISIS PERBANDINGAN KINERJA KEUANGAN BANK SYARIAH DEVISA DENGAN BANK SYARIAH NON DEVISA PERIODE 2012 2014

"apakah terdapat perbedaan antara kinerja keuangan Bank Syariah Devisa dan Bank Syariah Non Devisa jika dilihat dari aspek RGEC (Risk Profile, Good Corporate Governance (GCG), Earnings, dan Capital)?"

Adapun tujuan yang ingin dicapai dari penelitian ini antara lain:

1. menjelaskan kinerja Risk Profile, GCG, Earnings dan Capital pada Bank Syariah Devisa dan Bank Syariah Non Devisa.

2. Untuk mengetahui perbedaan tingkat kinerja keuangan Bank Syariah Devisa dan Bank Syariah Non Devisa dilihat dari aspek RGEC (Risk Profile, GCG, Earnings dan Capital .

\section{LANDASAN PUSTAKA}

Menurut Undang-Undang No. 21 Tahun 2008 tentang perbankan syariah adalah bank yang menjalankan kegiatan usahanya berdasarkan prinsip-prinsip syariah.

Dalam menjalankan usahanya, bank syariah memiliki 5 prinsip operasional yang harus dilaksanakan (Antonio, 2006) yang terdiri dari :

1. Prinsip Simpanan Murni (Al-Wadiah) Wadiah dapat diartikan sebagai titipan murni dari satu pihak ke pihak lain, baik individu maupun badan hukumyang harus dijaga dan dikembalikan kapan saja sipenitip kehendaki (Sudarsono, 2004:57).

\section{Bagi Hasil}

Bagi hasil merupakan suatu sistem yang mencakup tata cara pembagian hasil usaha antara pemilik modal dan pengelola modal. "Pembagian hasil usaha ini dapat terjadi antara bank dengan penyimpan dana, maupun antar bank dengan nasabah penerima dana" (Antonio, 2006).

3. Mudharabah

Menurut PSAK no 59,

"Mudharabah adalah akad kerjasama usaha antara shahibul mal (pemilik dana) dan mudharib (pengelola dana) dengan nisbah bagi hasil menurut kesepakatan dimuka"

4. Musyarakah

Hasil keuntungan dibagihasilkan sesuai dengan kesepakatan bersama diawal sebelum melakukan usaha, sedangkan kerugian ditanggung secara proporsional sampai batas modal masing masing" (Muhamad, 2004: 80).

5. Prinsip Jual Beli dan Margin Keuntungan

Antonio(2006 : 18) menyatakan bahwa,

"Prinsip ini merupakan sistem yang menerapkan tata cara jual beli, dimana bank akan membeli terlebih dahulu barang yang dibutuhkan atau mengangkat nasabah sebagai agen bank melakukan pembelian barang atas nama bank, kemudian menjual barang tersebut kepada nasabah denga harga sejumlah harga beli ditambah keuntungan".

6. Prinsip Sewa (ljarah)

ijarah adalah akad pemindahan hak guna atas barang atau jasa, melalui pembayaran upah sewa, tanpa diikuti dengan pemindahan kepemilikan (ownership/milkiyah) atas barang itu sendiri"(Antonio, 2001:117).

7. Prinsip Fee (Jasa) 
Muhayati, et al/Jurnal Ekonomi Syariah Teori dan Terapan Vol. 4 No. 2 Februari 2017: 101-116; ANALISIS PERBANDINGAN KINERJA KEUANGAN BANK SYARIAH DEVISA DENGAN BANK SYARIAH NON DEVISA PERIODE 2012 2014

Prinsip ini meliputi seluruh layanan nonpembiayaan yang diberikan bank (Antonio,dkk, 2006: 18) yaitu: wakalah, kafalah, hawalah, rahn, dan qardh.

Bank devisa adalah bank yang dapat melaksanakan transaksi ke luar negeri atau yang berhubungan dengan mata vang asing secara keseluruhan. (Soemitra, 2009:61). Seperti transfer ke luar negeri, transaksi ekspor impor, dan jasajasa lainya yang sesuai ketentuan Bank Indonesia (BI). Dengan demikian, bank devisa dapat melayani secara langsung transaksi-transaksi dalam skala internasional.

Bank non devisa adalah "bank yang belum mempunyai izin untuk melakukan transaksi sebagai bank devisa, transaksiyang dilakukan masih dalam batas-batas suatu negara" (Kasmir, 2004:30).

Pengertian laporan keuangan menurut PSAK No.01 2009:

"Laporan keuangan adalah suatu penyajian terstruktur dari posisi keuangan dan kinerja kevangan suatu entitas, untuk memberikan informasi mengenai posisi keuangan, kinerja keuangan, dan arus kas entitas yang bermanfaat bagi sebagian besar kalangan pengguna laporan keuangan dalam pembuatan keputusan ekonomi. Laporan keuangan juga menunjukkan hasil pertanggungjawaban manajemen atas penggunaan sumber daya yang dipercayakan kepada mereka"

Menurut Febriani dan Zulfan (2003:42)

Kinerja merupakan hal penting yang harus dicapai oleh setiap perusahaan atau perbankan dimanapun, karena kinerja merupakan cerminan dari kemampuan perusahaan dalam mengelola dan mengalokasikan sumber dayanya.

Sesuai dengan Peraturan Bank Indonesia Nomor 13/1/PBI/2011 tentang Penilaian Tingkat Kesehatan Bank Umum, bank wajib melakukan penilaian Tingkat Kesehatan Bank berdasarkan risiko dengan metode RGEC dengan pedoman selengkapnya mengacu pada Surat Edaran Bank Indonesia No.13/24/DPNP tanggal 25 Oktober 2011 yaitu :

1. Risk Profile (Profil Risiko)

Penilaian terhadap faktor profil risiko merupakan penilaian terhadap risiko inheren yang merupakan penilaian atas risiko yang melekat pada kegiatan bisnis bank, baik yang dapat dikuantifikasikan maupun yang tidak, yang berpotensi mempengaruhi potensi keuangan, dan kualitas penerapan manajemen risiko dalam operasional bank yang dilakukan terhadap 8 (delapan) risiko yaitu risiko kredit, risiko pasar, risiko likuiditas, risiko operasional, risiko hukum, risiko reputasi, stratejik, risiko kepatuhan beserta beberapa parameter atau indikator minimum yang wajib dijadikan acuan oleh bank dalam menilai risiko inheren.

2.Good Corporate Governance (GCG)

Good Corporate governance atau tata kelola perusahaan adalah sistem yang digunakan dalam mengarahkan dan mengendalikan kegiatan bisnis perusahaan (Ali, 2006:334). Berdasarkan Peraturan Bank Indonesia No 
Muhayati, et al/Jurnal Ekonomi Syariah Teori dan Terapan Vol. 4 No. 2 Februari 2017: 101-116; ANALISIS PERBANDINGAN KINERJA KEUANGAN BANK SYARIAH DEVISA DENGAN BANK SYARIAH NON DEVISA PERIODE 2012 2014

13/1/2011 yang mewajibkan bank-bank di Indonesia memasukkan faktor Good Corporate Governance ke dalam salah satu penilaian tingkat kesehatan bank, maka perusahaan dirasa sangat perlu untuk memiliki tanggung jawab yang besar dalam menjaga stabilitas sistem perbankannya sehingga dapat memperoleh predikat penerapan tata kelola perusahaan yang sehat (Good Corporate Governance).

Indikator penilaian GCG yaitu menggunakan bobot penilaian berdasarkan nilai komposit dari ketetapan Bank Indonesia menurut PBI No. 13/1/PBI/2011 Tentang Penilaian Tingkat Kesehatan Bank Umum. Peraturan Bank Indonesia mengenai Kesehatan GCG Bank Umum yang terdiri dari

a. Pelaksanaan tugas dan tanggung jawab Dewan Komisaris

b. Pelaksanaan tugas dan tanggung jawab Direksi

c. Kelengkapan dan pelaksanaan tugas komite-komite

d. Pelaksanaan tugas dan tanggung jawab Dewan Pengawas Syariah

e. Pelaksanaan prinsip syariah dalam kegiatan penghimpunan dana dan penyaluran dana serta pelayanan jasa.

f. Penanganan benturan kepentingan

g. Penerapan fungsi kepatuhan Bank

h. Penerapan fungsi audit intern

i. Penerapan fungsi audit ekstern

j. Batas Maksimum Penyaluran Dana k. Transparansi kondisi keuangan dan non keuangan, laporan pelaksanaan GCG dan pelaporan internal

3.Earnings (Rentabilitas)

Analisis rasio rentabilitas adalah alat untuk menganalisis atau mengukur tingkat efisiensi usaha dan profitabilitas yang dicapai oleh bank yang bersangkutan (Margaretha, 2009:61).

4. Capital (Permodalan)

Modal bank adalah dana yang diinvestasikan oleh pemilik dalam rangka pendirian badan usaha yang dimaksudkan untuk membiayai kegiatan usaha bank disamping untuk memenuhi regulasi yang ditetapkan oleh otoritas moneter (Taswan, 2010:137).

Hipotesis

$\mathrm{H}_{0}$ : Tidak Terdapat perbedaan yang signifikan antara kinerja kevangan bank syariah devisa dengan bank syariah non devisa berdasarkan aspek RGEC yaitu Risk profile (NPF dan FDR), GCG, Earnings (ROA dan NIM), Capital (CAR)

$\mathrm{H}_{1}$ : Terdapat perbedaan yang signifikan antara kinerja keuangan bank syariah devisa dengan bank syariah non devisa berdasarkan aspek RGEC yaitu Risk profile (NPF dan FDR), GCG, Earnings (ROA dan NIM), Capital (CAR)

\section{METODE PENELITIAN}

Pendekatan penelitian yang digunakan dalam penelitian ini adalah pendekatan penelitian kuantitatif. Adapun jenis variabel yang digunakan dalam penelitian ini yaitu sesuai Surat 
Muhayati, et al/Jurnal Ekonomi Syariah Teori dan Terapan Vol. 4 No. 2 Februari 2017: 101-116; ANALISIS PERBANDINGAN KINERJA KEUANGAN BANK SYARIAH DEVISA DENGAN BANK SYARIAH NON DEVISA PERIODE 2012 2014

Edaran Bank Indonesia Nomor 13/24/DPNP tanggal 25 Oktober 2011 Perihal Tingkat Kesehatan Bank Umum sebagai berikut:

Tabel 2.

Variabel Penelitian

\begin{tabular}{|c|c|}
\hline Variabel & Indikator Penelitian \\
\hline \multirow[t]{2}{*}{$\begin{array}{c}\text { Risk } \\
\text { Profile }\end{array}$} & $\begin{array}{l}\text { Risiko Kredit } \\
\text { NPF } \\
=\frac{\text { Kredit Kualitas Rendah }}{\text { Total Kredit }} \times 100 \%\end{array}$ \\
\hline & $\begin{array}{l}\text { Risiko Likuiditas } \\
\text { FDR } \\
=\frac{\text { Total Pendanaan }}{\text { Total Dana Pihak Ketiga }} \times 100 \%\end{array}$ \\
\hline GCG & $\begin{array}{l}\text { Hasil pelaksanaan prinsip- } \\
\text { prinsip GCG } \\
\text { sebagaimana diatur dank } \\
\text { ketentuan Bank Indonesia } \\
\text { mengenai GCG bagi Bank } \\
\text { Umum yang dilakukan secara } \\
\text { self assessment oleh pihak } \\
\text { Bank yang bersangkutan. }\end{array}$ \\
\hline \multirow[t]{2}{*}{ Earnings } & $\begin{array}{l}\text { ROA } \\
=\frac{\text { Laba Sebelum Pajak }}{\text { Rata }- \text { rata Total Aset }} \times 100 \%\end{array}$ \\
\hline & $\begin{array}{l}\text { NOM } \\
=\frac{(\mathrm{PO}-\mathrm{DBH})-\mathrm{BO}}{\text { Rata }- \text { rata Total Aset Produktif }}\end{array}$ \\
\hline Capital & $\begin{array}{l}\text { CAR } \\
=\frac{\text { Modal }}{\text { Aktiva Tertimbang Menurt }}\end{array}$ \\
\hline
\end{tabular}

Sumber : Lampiran Surat Edaran Bank Indonesia No. 13/24/DPNP

\section{Definisi Operasional Variabel}

Definisi operasional variabel-variabel yang telah ditentukan untuk penelitian ini pada periode 2012-2014 adalah sebagai berikut:
1. Risiko Kredit (Non Performing Financing)

Rasio NPF menunjukkan kemampuan manajemen bank dalam mengelola kredit bermasalah yang diberikan oleh bank. dimana nilai NPF adalah nilai kredit kualitas rendah pada total kredit. NPF dihitung dengan persamaan:

$$
\mathrm{NPF}=\frac{\text { Kredit Bermasalah }}{\text { Total Kredit }} \times 100 \%
$$

2. Risiko Likuiditas (Financing to Deposit Ratio)

Risiko likuiditas diukur dengan FDR (Financing to Deposit Ratio). FDR merupakan indikator dalam mengukur kemampuan bank dalam membayar kembali penarikan dana yang dilakukan oleh deposan dengan mengandalkan kredit yang diberikan sebagai sumber likuiditasnya. FDR dihitung persamaan:

$$
\mathrm{FDR}=\frac{\text { Total Pendanaan }}{\text { Total Dana Pihak Ketiga }} \times 100 \%
$$

3. Penilaian Good Corporate Governance (GCG)

Peneliti menganalisis laporan GCG berdasarkan prinsip-prinsip GCG yang mengacu Surat Edaran Bank Indonesia. Dalam penilaian GCG, digunakan metode penilaian sebelas indikator yang kemudian dinilai dengan peringkat komposit. Dalam menghitung nilai dari sebelas indikator penilaian GCG serta perolehan peringkat komposit, peneliti tidak menghitung sendiri melainkan mengambil dari laporan GCG tiap bank.

\section{Earnings(Rentabilitas)}


Muhayati, et al/Jurnal Ekonomi Syariah Teori dan Terapan Vol. 4 No. 2 Februari 2017: 101-116; ANALISIS PERBANDINGAN KINERJA KEUANGAN BANK SYARIAH DEVISA DENGAN BANK SYARIAH NON DEVISA PERIODE 2012 2014

Earnings (Rentabilitas) diukur dengan menggunakan ROA (Return On Aseet) yaitu rasio yang digunakan untuk mengukur kemampuan bank menghasilkan keuntungan secara relatif dibandingkan dengan total asetnya. Persamaan ROA adalah sebagai berikut:

$$
\text { ROA }=\frac{\text { Laba Sebelum Pajak }}{\text { Rata }- \text { rata Total Aset }} \times 100 \%
$$

Selain ROA rasio yang digunakan dalam mengukur Earnings menurutketentuan Bank Indonesia dalam Peraturan Bank Indonesia No.13/1/PBI/2011, yaitu Net Operating Margin (NOM) untuk mengetahui kemampuan aktiva produktif dalam menghasilkan laba. Adapun persamaan NOM adalah sebagai berikut:

$$
\text { NOM }=\frac{(\mathrm{PO}-\mathrm{DBH})-\text { BO }}{\text { Rata }- \text { rata Total Aset Produktif }} \times 100 \%
$$

5. Capital (Permodalan)

Permodalandiukur dengan menggunakan Capital Adequacy Ratio(CAR), yaitu besarnya jumlah kecukupan modal minimum yang dibutuhkan untuk dapat menutupi risiko kerugian yang mungkin timbul dari penanaman aktiva-aktiva yang mengandung risiko serta membiayai seluruh aktiva tetap dan inventaris bank. Adapun persamaan CAR yaitu:

$$
\text { CAR }=\frac{\text { Modal }}{\text { Aktiva Tertimbang Menurut Risiko }} \times 100
$$

\section{Jenis dan Sumber Data}

Dalam penelitian ini digunakan jenis data kuantitatif berupa data sekunder. Data sekunder yang digunakan dalam penelitian ini berupa laporan kevangan dan laporan GCG bank Syariah devisa dan non devisa periode
2012-2014. Data diperoleh dari website perusahaan perbankan syariah masingmasing dan laporan publikasi yang ada di situs www.ojk.go.id.

\section{Populasi dan Sampel}

Populasi dari penelitian ini adalah Seluruh Bank Umum Syariah yang terdaftar di Bank Indonesia selama tahun 2012-2014 yang berjumlah dua belas yakni BCA Syariah, Bank Muamalat Syariah, Bank Syariah Mandiri, BNI Syariah, BRI Syariah, Bank Panin Syariah, Bank Victoria Syariah, Bank Bukopin Syariah, Bank Mega Syariah, Maybank Syariah, BJB Syariah, dan BTPN Syariah.

Teknik pengambilan sampel yang digunakan adalah purposive sampling. Adapun kriteria pemilihan sampel penelitian ini adalah sebagai berikut: 1. Bank Umum Syariah yang termasuk dalam jenis Bank Syariah Devisa dan Bank Syariah non Devisa.

2. Bank Umum Syariah yang melakukan publikasi laporan keuangan tahunan dan laporan GCG berturut-turut selama tiga periode terakhir yang dapat diakses melalui website Otoritas Jasa Keuangan maupun website perusahaan masing-masing.

3. Bank Umum Syariah tersebut mempunyai semua data yang diperlukan secara lengkap.

Sehingga berdasarkan kriteria diatas, maka sampel bank yang terpilih untuk dijadikan sampel dapat dilihat pada tabel dibawah ini: 
Muhayati, ef al/Jurnal Ekonomi Syariah Teori dan Terapan Vol. 4 No. 2 Februari 2017: 101-116; ANALISIS PERBANDINGAN KINERJA KEUANGAN BANK SYARIAH DEVISA DENGAN BANK SYARIAH NON DEVISA PERIODE 2012 2014

Tabel 3.

Sampel Bank Syariah Devisa dan Bank Syariah Non Devisa

\begin{tabular}{|c|c|c|c|}
\hline No & $\begin{array}{c}\text { Bank Syariah } \\
\text { Devisa }\end{array}$ & No & $\begin{array}{c}\text { Bank Syariah } \\
\text { Non Devisa }\end{array}$ \\
\hline 1 & $\begin{array}{l}\text { Bank Syariah } \\
\text { Mandiri }\end{array}$ & 1 & BRI Syariah \\
\hline 2 & $\begin{array}{l}\text { Bank } \\
\text { Muamalat }\end{array}$ & 2 & BCA Syariah \\
\hline 3 & $\begin{array}{ll}\text { Bank } & \text { Mega } \\
\text { Syariah } & \end{array}$ & 3 & $\begin{array}{c}\text { Bank Bukopin } \\
\text { Syariah }\end{array}$ \\
\hline \multirow[t]{3}{*}{4} & BNI Syariah & 4 & $\begin{array}{l}\text { Bank Panin } \\
\text { Syariah }\end{array}$ \\
\hline & & 5 & $\begin{array}{l}\text { Bank BJB } \\
\text { Syraiah }\end{array}$ \\
\hline & & 6 & $\begin{array}{c}\text { Bank Victoria } \\
\text { Syariah }\end{array}$ \\
\hline
\end{tabular}

Sumber: Website OJK (www.ojk.go.id)

\section{Teknik Analisis Data}

Untuk menganalisis masalah yang telah dirumuskan dalam penelitian ini ditempuh dengan langkah langkah sebagai berikut :

1. Menghitung komponen RGEC dalam penelitian ini, antara lain :

a. Menghitung risiko kredit dengan menggunakan persamaan :

$$
\begin{aligned}
& \text { NPF } \\
& =\frac{\text { Kredit Kualitas Rendah }}{\text { Total Kredit }} \times 100 \%
\end{aligned}
$$

b. Menghitung risiko likuiditas dengan menggunakan persamaan:

FDR

$$
=\frac{\text { Total Pendanaan }}{\text { Total Dana Pihak Ketiga }} \times 100 \%
$$

c. Melakukan penilaian pada Good Corporate Governance (GCG) dengan cara mengalikan bobot penilaian masing-masing aspek GCG dengan peringkatnya, setelah itu menjumlahkan setiap hasilnya untuk menmdapatkan skor dari GCG.

d. Menghitung rasio rentabilitas dengan menggunakan persamaan:

$$
\begin{aligned}
\mathrm{ROA} & =\frac{\text { Laba Sebelum Pajak }}{\text { Rata }- \text { rata Total Aset }} \times 100 \% \\
\mathrm{NOM} & =\frac{(\mathrm{PO}-\mathrm{DBH})-B O}{\text { Rata" Total Aset Produktif }} \times 100 \%
\end{aligned}
$$

e. Menghitung rasio permodalan dengan menggunakan persamaan:

$$
\text { CAR }=\frac{\text { Modal }}{\text { ATMR }} \times 100 \%
$$

2. Hasil rasio kemudian dikelompokan menurut kelompok bank yang telah ditentukan dan berdasarkan tahun masing masing,

3. Uji Asumsi Klasik

Dalam penelitian ini sebenarnya diarahkan pada uji statistik parametik yaitu uji beda $\dagger$ saling bebas (independent sample t-test) karena jenis data yang digunakan adalah data rasio, Jika ada data yang tidak terdistribusi secara normal, maka pengujian hipotesis dapat dilakukan dengan statistik non parametrik (Mann Whitney Test).

1. Uji Normalitas

Dalam pengujian ini, pengujian normal tidaknya distribusi data akan diuji dengan uji normalitas Kolmogrov Smirnov dengan tingkat signifikansi yang digunakan sebesar 5\%. Pedoman pengambilan keputusan untuk 
Muhayati, et al/Jurnal Ekonomi Syariah Teori dan Terapan Vol. 4 No. 2 Februari 2017: 101-116; ANALISIS PERBANDINGAN KINERJA KEUANGAN BANK SYARIAH DEVISA DENGAN BANK SYARIAH NON DEVISA PERIODE 2012 -

hasil pengujian normalitas data adalah:

1. Jika nilai signifikasi atau nilai probabilitas < 0,05 maka tolak HO, artinya distribusi data tidak normal

2. Jika nilai signifikasi atau nilai probabilitas $>0,05$, maka terima HO,artinya distribusi data adalah normal

2. Uji hipotesis

Apabila pengujian statistik dilakukan dengan menggunakan Independent sample t-Test, maka akan melewati dua tahapan analisis. Tahap pertama adalah menguji apakah t-Test dilakukan dengan asumsi varians yang sama atau tidak. Pengujian ini dilakukan dengan Levene's Test. Jika angka probabilitas (significance value) Levene's Test lebih besar dari 0,05 maka test akan dilakukan dengan asumsi varians yang sama (equal variance assumed), sedangkan jika nilainya lebih kecil dari 0,05 maka t-Test akan dilakukan dengan asumsi varians tidak sama (equal varians not assumed).

Tahapan yang kedua adalah mengambil keputusan mengambil berdasarkan hasil independent sample t-test dan berdasarkan hasil analisis tahap pertama. Apabila angka probabilitas (significant value) dari hasil t-test menunjukan nilai yang lebih besar dari 0,05 berarti hipotesis dalam penelitian ini tidak dapat diterima, sedangkan jika angka probabilitas lebih kecil dari 0,05 maka hipotesis diterima. Sedangkan apabila pengujain statistik dilakukan dengan Mann Whitney Test, hipotesis akan diterima jika nilai probabilitas kurang dari 0,05 dan hipotesis tidak dapat diterima bila nilai probabilitas lebih besar dari 0,05.

\section{HASIL PENELITIAN DAN PEMBAHASAN}

Uji Hipotesis Kinerja Keungan untuk Risiko Kredit (NPF)

Tabel 4.

Mann Whitney Test Variabel NPF

\begin{tabular}{|c|c|c|c|c|}
\hline $\begin{array}{c}\text { Varia } \\
\text { bel }\end{array}$ & Bank & $\begin{array}{c}\text { Me } \\
\text { an } \\
\text { Ran } \\
k\end{array}$ & $\begin{array}{c}\text { Significa } \\
\text { nce } \\
\text { value }\end{array}$ & $\begin{array}{c}\text { Keteran } \\
\text { gan }\end{array}$ \\
\hline \multirow{8}{*}{$\begin{array}{c}\text { Risiko } \\
\text { Kredit } \\
\text { (NPF) }\end{array}$} & Bank & 15.7 & \multirow{8}{*}{0.899} & \multirow{8}{*}{$\begin{array}{c}\mathrm{HO} \\
\text { diterima } \\
\text { (Tidak } \\
\text { ada } \\
\text { Perbed } \\
\text { aan } \\
\text { Signifika } \\
\text { n) }\end{array}$} \\
\hline & Syari & 5 & & \\
\hline & ah & & & \\
\hline & $\begin{array}{c}\text { Devis } \\
\text { a }\end{array}$ & & & \\
\hline & Bank & 15.3 & & \\
\hline & $\begin{array}{c}\text { Syari } \\
\text { ah }\end{array}$ & 3 & & \\
\hline & Non & & & \\
\hline & a & & & \\
\hline
\end{tabular}

Berdasarkan hasil uji beda Mann-Whitney Test, diketahui bahwa rata rata ranking (mean rank) variabel NPF pada Bank Syariah Devisa (16.67) lebih besar dibandingkan dengan Bank Syariah Non Devisa (14.72). Sementara nilai signifikansinya 0.553. Angka tersebut lebih besar dari 0.05 sehingga menunjukkan tidak adanya perbedaan yang signifikan antara kinerja kevangan Bank Syariah 
Muhayati, et al/Jurnal Ekonomi Syariah Teori dan Terapan Vol. 4 No. 2 Februari 2017: 101-116; ANALISIS PERBANDINGAN KINERJA KEUANGAN BANK SYARIAH DEVISA DENGAN BANK SYARIAH NON DEVISA PERIODE 2012 2014

Devisa dengan Bank Syariah Non Devisa berdasarkan risk profile dengan penilaian risiko kredit (NPF) .

Uji Hipotesis Kinerja Keungan untuk Risiko Likuiditas (FDR)

Tabel 5.

Lavene's Test

\begin{tabular}{|c|c|c|c|}
\hline \multirow{2}{*}{ Variabel } & \multicolumn{2}{|c|}{$\begin{array}{c}\text { Levene's test for } \\
\text { equality of } \\
\text { variance }\end{array}$} & Keterangan \\
\hline \multirow{2}{*}{$\begin{array}{c}\text { Risiko } \\
\text { Likuiditas }\end{array}$} & $\mathbf{F}$ & Sig & Homogen \\
\cline { 2 - 3 } & 1.542 & 0.225 & \\
\hline
\end{tabular}

Tabel 6.

Independent Sample t-test

\begin{tabular}{|l|l|c|l|}
\hline \multicolumn{4}{|c|}{ Independent t-test } \\
\hline \multirow{2}{*}{$\begin{array}{l}\text { Risiko } \\
\text { Likuiditas }\end{array}$} & $\begin{array}{c}\text { Sig. } \\
\mathbf{( 2} \\
\text { tailed) }\end{array}$ & Keterangan \\
& $\begin{array}{l}\text { Equal } \\
\text { variances } \\
\text { Assumed }\end{array}$ & 0.731 & $\begin{array}{l}\text { Ho diterima } \\
\text { (Tidak ada } \\
\text { perbedaan } \\
\text { signifikan) }\end{array}$ \\
\cline { 2 - 4 } & $\begin{array}{l}\text { Equal } \\
\text { variances } \\
\text { not } \\
\text { assumed }\end{array}$ & 0.697 & \\
\hline
\end{tabular}

Dari tabel 6. diketahui nilai sigifikansi dari hasil uji Levene's test lebih besar dari $0,05(<0,05)$ yaitu 0.225 sehingga hasil uji yang digunakan yaitu Equal Variances Assumed. Berdasarkan Independent sample t-test (Equal Variances Assumed), nilai signifikansi variabel risiko likuiditas (FDR) lebih besar dari $0,05(>0,05)$ yaitu 0.731. Hal ini menunjukkan tidak adanya perbedaan yang signifikan antara kinerja keuangan bank syariah devisa dengan bank syariah non devisa berdasarkan risk profile dengan menggunakan penilaian risiko likuiditas (FDR).
Uji Hipotesis Kinerja Keuangan untuk GCG

Tabel 7.

Lavene's Test

\begin{tabular}{|c|c|c|c|}
\hline \multirow{2}{*}{ Variabel } & \multicolumn{2}{|c|}{$\begin{array}{c}\text { Levene's test for } \\
\text { equality of } \\
\text { variance }\end{array}$} & Keterangan \\
\hline \multirow{2}{*}{ GCG } & $\mathbf{F}$ & Sig & \multirow{2}{*}{ Homogen } \\
\cline { 2 - 3 } & 3.921 & 0.058 & Homong \\
\hline
\end{tabular}

Tabel 8.

Independent Samples t-test

\begin{tabular}{|c|l|c|c|}
\hline \multicolumn{4}{|c|}{ Independent t-test } \\
\hline \multirow{2}{*}{ GCG } & $\begin{array}{c}\text { Sig. } \\
\mathbf{( 2} \\
\text { tailed) }\end{array}$ & Keterangan \\
\hline \multirow{6}{*}{} & $\begin{array}{l}\text { Equal } \\
\text { variances } \\
\text { Assumed }\end{array}$ & 0.594 & $\begin{array}{l}\text { Ho diterima } \\
\text { (Tidak ada } \\
\text { perbedaan } \\
\text { signifikan) }\end{array}$ \\
\cline { 2 - 4 } & $\begin{array}{l}\text { Equal } \\
\text { variances } \\
\text { not } \\
\text { assumed }\end{array}$ & 0.633 & \\
\hline
\end{tabular}

Dari tabel pertama diketahui nilai sigifikansi dari hasil uji Levene's test lebih besar dari 0,05 $(<0,05)$ yaitu 0.058, sehingga hasil uji yang digunakan yaitu Equal Variances Assumed. Berdasarkan Independent samples t-test (Equal Variances Assumed), nilai signifikansi variabel GCG lebih besar dari 0,05 (> 0,05 ) yaitu 0,594. Hal ini menunjukkan tidak adanya perbedaan yang signifikan antara kinerja kevangan bank syariah devisa dengan bank syariah non devisa berdasarkan penilaian GCG.

\section{Uji Hipotesis Kinerja Keuangan untuk Earnings (ROA)}

Tabel 9.

Lavene's Test

\begin{tabular}{|c|c|c|c|}
\hline Variabel & \multicolumn{2}{|c|}{$\begin{array}{l}\text { Levene's test for } \\
\text { equality of } \\
\text { variance }\end{array}$} & Keterangan \\
\hline & $F$ & Sig & \\
\hline$R O A$ & 0.157 & 0.695 & Homogen \\
\hline
\end{tabular}


Muhayati, et al/Jurnal Ekonomi Syariah Teori dan Terapan Vol. 4 No. 2 Februari 2017: 101-116; ANALISIS PERBANDINGAN KINERJA KEUANGAN BANK SYARIAH DEVISA DENGAN BANK SYARIAH NON DEVISA PERIODE 2012 2014

Tabel 10.

Independent Sample t-test

\begin{tabular}{|c|c|c|c|}
\hline \multicolumn{4}{|c|}{ Independent t-test } \\
\hline & & $\begin{array}{c}\text { Sig. } \\
(2 \\
\text { tailed }) \\
\end{array}$ & Keterangan \\
\hline \multirow[t]{2}{*}{ ROA } & $\begin{array}{l}\text { Equal } \\
\text { variances } \\
\text { Assumed }\end{array}$ & 0.157 & $\begin{array}{c}\text { Ho diterima } \\
\text { (Tidak ada } \\
\text { perbedaan } \\
\text { signifikan) }\end{array}$ \\
\hline & $\begin{array}{l}\text { Equal } \\
\text { variances } \\
\text { not } \\
\text { assumed }\end{array}$ & 0.695 & \\
\hline
\end{tabular}

Dari tabel pertama diketahui nilai sigifikansi dari hasil uji Levene's test lebih besar dari $0,05(<0,05)$ yaitu 0.695 , sehingga hasil uji yang digunakan yaitu Equal Variances Assumed. Berdasarkan Independent Sample T-test (Equal Variances Assumed), nilai signifikansi variabel ROA lebih besar dari 0,05 $(>0,05)$ yaitu 0.157. Hal ini menunjukkan tidak adanya perbedaan yang signifikan antara kinerja keuangan bank syariah devisa dengan bank syariah non devisa berdasarkan penilaian ROA.

Uji Hipotesis Kinerja Keuangan untuk Earnings (NOM)

Tabel 11.

Lavene's Test

\begin{tabular}{|c|c|c|c|}
\hline \multirow{2}{*}{ Variabel } & \multicolumn{2}{|c|}{$\begin{array}{c}\text { Levene's test for } \\
\text { equality of } \\
\text { variance }\end{array}$} & Keterangan \\
\hline \multirow{2}{*}{ NOM } & $\mathbf{F}$ & Sig & \multirow{2}{*}{ Homogen } \\
\cline { 2 - 3 } & 0.288 & 0.596 & Hom \\
\hline
\end{tabular}

Tabel 12.

Indepnedent Sample t-test

\begin{tabular}{|c|l|c|c|}
\hline \multicolumn{3}{|c|}{ Independent t-test } \\
\hline & & $\begin{array}{c}\text { Sig. } \\
\mathbf{( 2} \\
\text { tailed) }\end{array}$ & Keterangan \\
\hline \multirow{3}{*}{$\mathrm{N}$} & Equal variances & 0.006 & $\begin{array}{c}\text { Ho ditolak } \\
\text { (ada } \\
\text { perbedaan } \\
\text { signifikan) }\end{array}$ \\
$\mathrm{M}$ & Assumed & & \\
\cline { 2 - 4 } & $\begin{array}{l}\text { Equal variances } \\
\text { not assumed }\end{array}$ & 0.010 & \\
\hline
\end{tabular}

Dari tabel pertama diketahui nilai sigifikansi dari hasil uji Levene's test lebih besar dari 0,05(< 0,05) yaitu 0.596, sehingga hasil uji yang digunakan yaitu Equal Variances Assumed. Berdasarkan Independent sample t-test (Equal Variances Assumed), nilai signifikansi variabel NOM lebih kecil dari 0,05 $(<0,05)$ yaitu 0.006 . Hal ini menunjukkan adanya perbedaan yang signifikan antara kinerja keuangan Bank Syariah Devisa dengan Bank Syariah Non Devisa berdasarkan penilaian NOM. Uji Hipotesis Kinerja Keuangan untuk
Capital (CAR)

Tabel 13.

Hasil Uji Mann-Whitney Test variabel CAR

\begin{tabular}{|c|c|c|c|c|}
\hline $\begin{array}{c}\text { Variab } \\
\text { el }\end{array}$ & Bank & $\begin{array}{c}\text { Mea } \\
\text { n } \\
\text { Ran } \\
k\end{array}$ & $\begin{array}{l}\text { Significan } \\
\text { ce value }\end{array}$ & $\begin{array}{c}\text { Keterang } \\
\text { an }\end{array}$ \\
\hline \multirow[t]{2}{*}{$\begin{array}{c}\text { Capit } \\
\text { al } \\
\text { (CAR) }\end{array}$} & $\begin{array}{c}\text { Bank } \\
\text { Syari } \\
\text { ah } \\
\text { Devis } \\
\text { a }\end{array}$ & $\begin{array}{l}11.7 \\
5\end{array}$ & \multirow[t]{2}{*}{0.057} & \multirow{2}{*}{$\begin{array}{c}\mathrm{H}_{0} \\
\text { diterima } \\
\text { (Tidak } \\
\text { ada } \\
\text { Perbeda } \\
\text { an } \\
\text { Signifikan } \\
\text { ) }\end{array}$} \\
\hline & $\begin{array}{c}\text { Bank } \\
\text { Syari } \\
\text { ah } \\
\text { Non } \\
\text { Devis } \\
\text { a }\end{array}$ & $\begin{array}{l}18.0 \\
0\end{array}$ & & \\
\hline
\end{tabular}

Berdasarkan hasil uji beda MannWhitney Test, diketahui bahwa rata rata ranking (mean rank) variabel CAR pada Bank Syariah Devisa (11.75) lebih kecil dibandingkan dengan Bank Syariah Non Devisa (18.00). Sementara nilai signifikansinya 0.057 . Angka tersebut lebih besar dari 0.05 sehingga menunjukkan tidak adanya perbedaan yang signifikan antara kinerja keuangan bank syariah devisa dengan bank syariah non devisa 
Muhayati, et al/Jurnal Ekonomi Syariah Teori dan Terapan Vol. 4 No. 2 Februari 2017: 101-116; ANALISIS PERBANDINGAN KINERJA KEUANGAN BANK SYARIAH DEVISA DENGAN BANK SYARIAH NON DEVISA PERIODE 2012 2014

berdasarkan aspek capital yang diukur dengan CAR.

\section{PEMBAHASAN}

\section{Risiko Kredit (Non Performing Financing)}

Berdasarkan uji beda yang telah dilakukan dengan menggunakan uji Mann-Whitney test hasil penelitian menunjukan tidak terdapat perbedaan yang signifikan antara kinerja keuangan bank syariah devisa dan bank syariah non devisa dilihat dari sisi risiko kredit yang dihitung dengan rasio NPF.

Dari analisis deskriptif NPF dapat diketahui bahwa Bank Syariah Devisa berisiko lebih kecil dan memiliki kinerja kevangan yang lebih baik dilihat dari aspek risiko kredit (NPF) debandingkan dengan Bank Syariah Non Devisa.

Tidak terdapatnya perbedaan kinerja keuangan Bank Syariah Devisa dengan Bank Syariah Non Devisa untuk risiko kredit yang diukur dengan rasio NPF ini disebabkan oleh adanya ketentuan dari Bank Indonesia bahwa bank yang beroperasi di Indonesia harus memiliki rasio NPF dengan nilai minimum sebesar 5\%. Sehingga Bank Syariah Devisa dan Bank Syariah Non Devisa berupaya untuk dapat memenuhi standar tersebut agar dapat dinyatakan memiliki kinerja keuangan yang baik dilihat dari aspek risiko kredit (NPF) dan agar dapat dinyatakan mempunyai manajemen yang baik dalam mengelola pembiayaan bermasalah yang dihadapi.

\section{Risiko Likuiditas (Financing Deposit Ratio)}

Dari hasil uji independent samples t-test FDR, menunjukan bahwasanya tidak terdapat perbedaan yang signifikan antara kinerja kevangan Bank Syariah Devisa dan Bank Syariah Non Devisa dilihat dari risiko likuiditas yang diukur dengan rasio FDR.

Akan tetapi hasil dari analisis deskriptif dapat dilihat bahwa bahwa Bank Syariah Devisa memiliki kinerja keuangan yang lebih baik dilihat dari aspek risiko likuidtas yang diukur dengan FDR dibandingkan dengan Bank Syariah Non Devisa dan menggambarkan Bank Syariah Devisa memiliki kemampuan yang baik dalam membayar kembali penarikan dana yang dilakukan deposan dengan mengandalkan pembiayaan yang diberikan sebagai sumber likuiditasnya dibandingakn dengan Bank Syariah Non Devisa.

Tidak terdapatnya perbedaan pada segi FDR untuk Bank Syariah Devisa dan Bank Syariah Non Devisa disebabkan oleh adanya ketentuan dari Bank Indonesia bahwa bank yang beroperasi di Indonesia harus memiliki rasio FDR dengan nilai minimum sebesar $85 \%$ sampai $110 \%$. Sehingga Bank Syariah Devisa dan Bank Syariah Non Devisa berupaya untuk dapat memenuhi standar tersebut agar dapat dinyatakan memiliki kinerja keuangan yang baik dari aspek risiko likuidtas dan agar dapat dinyatakan mempunyai manajemen yang baik dalam mengelola likuiditas bank.

\section{Good Corporate Gorvernance}

Berdasarkan uji yang telah dilakukan dengan menggunakan uji 
Muhayati, et al/Jurnal Ekonomi Syariah Teori dan Terapan Vol. 4 No. 2 Februari 2017: 101-116; ANALISIS PERBANDINGAN KINERJA KEUANGAN BANK SYARIAH DEVISA DENGAN BANK SYARIAH NON DEVISA PERIODE 2012 2014

Independent Samples T-test menunjukkan tidak adanya perbedaan yang signifikan antara kinerja keuangan Bank Syariah Devisa dengan Bank Syariah Non Devisa berdasarkan penilaian GCG. Hal ini berarti menunjukan bahwa Bank Syariah Devisa maupun Bank Syariah Non Devisa telah memiliki tanggung jawab yang besar dalam menjaga stabilitas sistem perbankanya karena telah sama-sama memperoleh penerapan tata kelola perusahaan yang sehat.

Jika dilihat dari hasil analisis deskriptif nilai GCG Bank Syariah Non Devisa lebih baik dari Bank Syariah Devisa.

Tidak terdapatnya perbedaan kinerja keungan bank syariah devisa dengan bank syariah non devisa untuk aspek GCG ini disebabkan oleh adanya ketentuan dari Bank Indonesia bahwa bank yang beroperasi di Indonesia harus memiliki peringkat komposit GCG dengan nilai komposit berkisar $1.5-2.53$ untuk dinyatakan sebagai bank berkategori Baik. Sehingga Bank Syariah Devisa dan Bank Syariah Non Devisa berupaya untuk dapat memenuhi standar tersebut agar dapat dinyatakan memiliki kinerja GCG yang baik. Karena dengan pengelolaan GCG yang baik maka akan mempengaruhi rentabilitas serta permodalan perbankan itu sendiri.

\section{Earnings (Rentabilitas)}

\section{Return On Asset (ROA)}

Dari hasil uji independent samples t-test menunjukkan tidak terdapat perbedaan yang signifikan antara kinerja keuangan Bank Syariah Devisa dan Bank Syariah Non Devisa dilihat dari sisi ROA. Hasil dari analisis deskriptif bahwa bank syariah devisa lebih baik dalam memperoleh laba bersih dengan memanfaatkan aktiva yang dimilikinya.

Tidak terdapatnya perbedaan dari segi rasio ROA yang dimiliki bank syariah devisa dan banyak syariah non devisa disebabkan olehadanya ketentuan dari Bank Indonesia bahwa bank yang beroperasi di Indonesia harus memiliki rasio ROA dengan nilai minimum sebesar 1,5\%. Sehingga Bank Syariah Devisa dan Bank Syariah Non Devisa berupaya untuk dapat memenuhi standar tersebut agar dapat dinyatakan memiliki kinerja keuangan yang baik dari aspek Earnings (rentabilitas) serta dinyatakan mempunyai manajemen yang baik dalam hal menghasilkan keuntungan secara relatif dibandingkan dengan total asetnya. Selain itu sebab tidak ada perbedaan karena adanya ketentuan dalam kepemilikan aset saat pendirian bank syariah itu sendiri.

\section{Net Operating Margin (NOM)}

Dari hasil uji hipotesis menggunakan uji independent samples ttestmenunjukkan adanya perbedaan yang signifikan antara kinerja kevangan Bank Syariah Devisa dengan Bank Syariah Non Devisa berdasarkan penilaian NOM.

Dilihat dari analisis deskriptif dapat diketahui bahwa bank syariah devisa lebih baik dalam mengelola aktiva produktif untuk menghasilkan laba perbankan.Dan dengan nilai NOM yang 
Muhayati, et al/Jurnal Ekonomi Syariah Teori dan Terapan Vol. 4 No. 2 Februari 2017: 101-116; ANALISIS PERBANDINGAN KINERJA KEUANGAN BANK SYARIAH DEVISA DENGAN BANK SYARIAH NON DEVISA PERIODE 2012 2014

sangat tinggi yaitu lebih dari $3 \%$ maka kedua jenis bank tersebut masuk dalam kategori bank yang sangat sehat.

Perbedaan yang timbul tersebut disebabkan oleh dalam operasionalnya bank syariah yang telah berpredikat sebagai bank devisa dapat melakukan transaksi tidak hanya didalam negeri, tetapi juga di luar negeri dalam bentuk valas. Aktiva dalam bentuk valas yang dimiliki bank syariah biasanya meliputi penempatan pada bank lain dalam bentuk valas, surat berharga yang dimiliki dalam bentuk valas, piutang murabahah dalam bentuk valas, pembiayaan dalam bentuk valas, dan aktiva lain yang berbentuk valas. Selain itu, adanya perbedaan disebabkan karena Bank Syariah Devisa memiliki tingkat laba yang tinggi karena Bank Syariah Devisa merupakan pemain lama yang sudah lebih lama beroperasi dibandingkan Bank Syariah Non Devisa.

\section{Capital (CAR)}

Dari hasil uji hipotesis menggunakan uji independent samples ttest menunjukkan bahwa tidak terdapat perbedaan yang signifikan antara kinerja kevangan Bank Syariah Devisa dan Bank Syariah Non Devisa dilihat dari sisi CAR.

Tidak terdapatnya perbedaan dari segi rasio CAR yang dimiliki bank syariah devisa dan banyak syariah non devisa disebabkan oleh adanya ketentuan tingkat rasio minimal CAR yang disyaratkan $\mathrm{BI}$ yaitu $8 \%$. Sehingga Bank Syariah Devisa dan Bank Syariah Non Devisa berupaya untuk dapat memenuhi standar tersebut agar dapat dinyatakan memiliki kinerja keuangan yang baik dari aspek permodalan dan agar dapat dinyatakan mempunyai manajemen yang baik dalam mengelola permodalan. Hal ini menunjukkan Baik Bank Syariah Devisa maupun Bank Syariah Non Devisa telah mampu memiliki struktur modal yang memadai untuk menunjang kebutuhannya dalam menjalankan kegiatan operasinya, karena semakin baik kecukupan modal yang dimiliki suatu bank maka nantinya bisa menambah kepercayaan masyarakat atau nasabah terhadap bank itu sendiri. Apalagi modal merupakan permulaan dalam pendirian Bank umum syariah dan merupakan faktor yang sangat penting demi keberlangsungan bank tersebut.

\section{Simpulan}

Berdasarkan hasil analisis dan pembahasan pada bab sebelumnya, maka dapat disimpulkan sebagai berikut:

1. Tidak terdapat perbedaan yang signifikan antara kinerja kevangan Bank Syariah Devisa dan Bank Syariah Non Devisa dilihat dari sisi Risiko Kredit yang ditunjukan oleh rasio NPF.

2. Tidak terdapat perbedaan yang signifikan antara kinerja keuangan Bank Syariah Devisa dan Bank Syariah Non Devisa dilihat dari sisi Risiko Likuiditas yang ditunjukan oleh rasio FDR

3. Tidak terdapat perbedaan yang signifikan antara kinerja kevangan 
Muhayati, et al/Jurnal Ekonomi Syariah Teori dan Terapan Vol. 4 No. 2 Februari 2017: 101-116; ANALISIS PERBANDINGAN KINERJA KEUANGAN BANK SYARIAH DEVISA DENGAN BANK SYARIAH NON DEVISA PERIODE 2012 2014

Bank Syariah Devisa dan Bank Syariah Non Devisa dilihat dari sisi GCG.

4. Tidak terdapat perbedaan yang signifikan antara kinerja keuangan Bank Syariah Devisa dan Bank Syariah Non Devisa dilihat dari sisi Earnings yang ditunjukan oleh rasio ROA

5. Terdapat perbedaan yang signifikan antara kinerja keuangan Bank Syariah Devisa dan Bank Syariah Non Devisa dilihat dari sisi Earnings yang ditunjukan oleh rasio NOM

6. Tidak terdapat perbedaan yang signifikan antara kinerja keuangan Bank Syariah Devisa dan Bank Syariah Non Devisa dilihat dari sisi Capital yang ditunjukan oleh rasio CAR.

\section{DAFTAR PUSTAKA}

Ali, Masyhud. (2006). Manajemen Risiko, Strategi Perbankan Dan Dunia Usah Menghadapi Tantangan Globalisasi Bisnis, PT. Raja Grafindo Persada.

Anshori, Musclich dan Sri Iswati. 2009. Buku Ajar Metodologi Penelitian Kuantitatif. Surabaya: Pusat Penerbitan dan Percetakan UNAIR (AUP)

Ansori, Abdul Ghofur. 2009. Perbankan Syari'ah di Indonesia. Yogyakarta: Gadjah Mada University Press

Antonio, M.Syafi'i. 2001. Bank Syariah, Dari Teori Ke Praktika. Jakarta: Gema Insani Antonio, M.Syafi'i. 2006. Bank Syariah, Dari Teori Ke Praktika. Jakarta: Gema Insani
DEPAG, 2002. Al-Quran dan terjemahanya. Jakarta: Salemba Empat.

Febriyani, Anita \& Rahadian Zulfadian. 2003. Analisis Kinerja Bank Devisa dan Bank Non Devisa DI Indonesia. Kajian Ekonomi dan Kevangan, 7(4): 38-

Ikatan Akuntansi Indonesia. 2009. ED PSAK No. 01 (Revisi 2009). Salemba Empat. Jakarta.

Kasmir, (2004). Bank dan Lembaga Keuangan Lainnya. Jakarta : PT. Raja Grafindo Persada.

Margaretha, Farah. 2009. Manajemen Keuangan Bagi Industri Jasa. Jakarta: Grasindo.

Muhammad, 2004. Manajemen Dana Bank Syariah. Yogyakarta: Ekonisia

Otoritas Jasa Keuangan. 2016. Laporan Kevangan Publikasi Bank. (Online) (http://www.ojk.go.id, diakses 28 februari 2016)

Republik Indonesia. Undang-Undang Republik Indonesia No.21 Tahun 2008 Tentang Perbankan Syariah. 2008. Jakarta

Republik Indonesia. Pernyataan Standar Akuntansi Keuangan (PSAK) No.59 tentang Akuntansi Perbankan Syariah. 2007. Jakarta

Ansori, Abdul Ghofur. Perbankan Syari'ah di Indonesia, (Yogyakarta: Gadjah Mada University Press, 2009), hlm 7.

Soemitra, Andri, 2009,Bank dan Lembaga Kevangan Syari'ah, Jakarta : Kencana. 
Muhayati, et al/Jurnal Ekonomi Syariah Teori dan Terapan Vol. 4 No. 2 Februari 2017: 101-116; ANALISIS PERBANDINGAN KINERJA KEUANGAN BANK SYARIAH DEVISA DENGAN BANK SYARIAH NON DEVISA PERIODE 2012 2014

Sudarsono, Heri. 2004.Bank Dan Lembaga

Kevangan Syariah. Yogyakarta:

Ekonisia

Surat Edaran Bank Indonesia Nomor

13/24/DPNP, 25 Oktober 2011 Tentang Penilaian Tingkat Kesehatan Bank Umum. Jakarta. 2011

Taswan. 2010. Manajemen Perbankan Konsep, Teknik, dan Aplikasi. Yogyakarta : UPP STIM YKPN

Wahyuningsih, Widya. 2012. Analisis Perbandingan Kinerja Keuangan Bank Umum Syariah dengan Bank Umum Konvensional $\mathrm{Di}$ Indonesia. Fakultas Ekonomi dan Bisnis Universitas Hasanuddin. 